\title{
ANALYSIS OF EULER-BERNOULLI AND TIMOSHENKO BEAMS BY THE BOUNDARY ELEMENT METHOD
}

\author{
J. A. M. Carrer ${ }^{1}$, W. J. Mansur ${ }^{2}$, R. F. Scuciato ${ }^{1}$, S. A. Fleischfresser ${ }^{1}$ \\ ${ }^{1}$ Programa de Pós-Graduação em Métodos Numéricos em Engenharia, PPGMNE/UFPR, Cu- \\ ritiba, Brasil (carrer@ufpr.br)
}

${ }^{2}$ Programa de Engenharia Civil, COPPE/UFRJ, Rio de Janeiro, Brasil

\begin{abstract}
Boundary element formulations for the static analysis of Euler-Bernoulli and Timoshenko beams are presented in this work. As the problems are stated in one dimension, the boundary is constituted only by the extreme nodes of the beam. The four usual types of beams, i.e. pinned-pinned, fixed-fixed, fixed-pinned and fixed-free are solved for a loading uniformly distributed along the length of the beam. The potentialities of the proposed formulations are assessed by comparing the numerical results with the analytical ones.
\end{abstract}

Keywords: Euler-Bernoulli beams, Timoshenko beams.

\section{INTRODUCTION}

This article is concerned with the solution of problems related to the Euler-Bernoulli and Timoshenko beams by the Boundary Element Method (BEM). It is important to mention that the analysis of beams by the BEM is a subject in which the method presents some features that have turned it one powerful tool for the solution of several problems in engineering and sciences in general: easiness computational implementation and high level of accuracy in the results.

Note that, as the problems are one-dimensional ones, the boundary is constituted only by the two nodes at the extremities of the beams: one node at $\mathrm{x}=0$ and the other node at $\mathrm{x}=\mathrm{L}$, if the beam with length $\mathrm{L}$ is located on the $\mathrm{x}$-axis with the left node at the origin. The domain discretization is required in both formulations, as one can see along the text, and is accomplished with the use of linear cells.

In the development presented here, initially the governing differential equations are presented and discussed. In the sequence, the BEM integral equations, obtained after following a weighting residual procedure, are presented.

The basic hypothesis of the Euler-Bernoulli beam theory, also called classical beam theory, states that the plane cross-sections, initially perpendicular to the axis of the beam, remain plane and perpendicular to the neutral axis after bending. The problem is described by only one differential equation. This matter is well discussed in several text books, for instance 
Graff [6], Rao [7]. A BEM approach can be found at the classic book by Brebbia, Telles and Wrobel [3]. Note that the problem presents two natural boundary conditions, namely, the bending moment and the shear force, and two essential boundary conditions, namely, the transverse displacement and the rotation of the cross-section. In this way, each boundary node presents four variables and, consequently, only one integral equation is not enough for the solution of the problem, an additional integral equation being required for its numerical solution. Starting from the basic integral equation, related to the transverse displacement, the required additional equation is obtained by taking the derivative of the former with respect to the field point coordinate; consequently, the additional equation is related to the rotation of the cross-section. A set of two integral equations is thus obtained and the problem can be solved appropriately. Note that each equation is applied to the boundary nodes and, consequently, the four equations, which are necessary for the solution, of the problem are obtained.

In the Timoshenko beam theory, e.g. Graff [6], Rao [7], Timoshenko [8], the effect of the shear deformation is taken into account, generating an improved theory that gives more reliable results than the classical one in dynamic analyses, especially for higher frequencies. The problem is described by a set of two differential equations. For this reason, the two BEM integral equations, necessary to the solution of the problem, are obtained quite naturally in this formulation. For BEM static analysis, the reader is referred to Antes [1].

The examples presented at the end of the article are constituted by the four usual kinds of beams, that is: pinned-pinned, fixed-fixed, fixed-pinned (fixed at $x=0$ and pinned at $x=L$ ) and fixed-free. A loading uniformly distributed along the length of the beam is considered in all analyses. The numerical results are compared with the corresponding analytical solutions. The good agreement observed between them shows that the BEM formulations are appropriate tools for the solution of static problems related to the Euler-Bernoulli and Timoshenko beam theories.

\section{THE EULER-BERNOULLI THEORY OF BEAMS}

The basic hypothesis of the Euler-Bernoulli states that the plane cross-sections, initially perpendicular to the axis of the beam, remain plane and perpendicular to the neutral axis after bending, e.g. Graff [6], Rao [7].

For the system of coordinates described in Figure 1, the governing equation of the problem is written as:

$$
\mathrm{EI} \frac{\mathrm{d}^{4} \mathrm{u}}{\mathrm{dx}^{4}}=\mathrm{q}(\mathrm{x})
$$

where $\mathrm{u}=\mathrm{u}(\mathrm{x})$ is the transverse displacement, $\mathrm{E}$ is the Young's modulus and $\mathrm{I}$ is the moment of inertia of the cross-section of area A, admitted constant. The loading, $q=q(x)$, is represented by a function of position. In the problems analyzed here, the loading is a constant function, uniformly distributed along the length of the beam.

The boundary conditions are: 
i) essentials:

$$
\begin{gathered}
u(x)=\bar{u}(x) \text { : transverse displacement } \\
\varphi(x)=\frac{d u}{d x}=\bar{\varphi}(x) \text { : rotation of the cross-section }
\end{gathered}
$$

ii) naturals:

$$
\begin{gathered}
-E I \frac{d^{2} u}{d x^{2}}=\bar{M}(x) \text { : bending moment } \\
-E I \frac{d^{3} u}{d x^{3}}=\bar{Q}(x) \text { : shear force }
\end{gathered}
$$

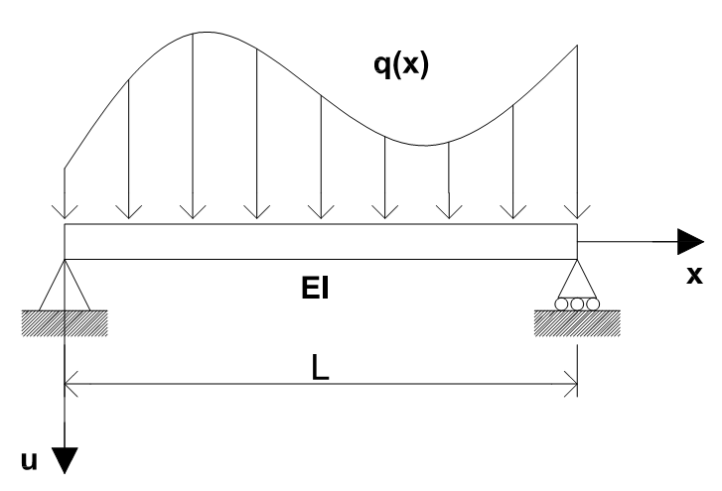

Figure 1. Beam under general loading.

\subsection{BEM Formulation to the Euler-Bernoulli Beam}

Applying a residual statement to Equation (1), in which the weighting function is the fundamental solution that satisfies Equation (6) below:

$$
\mathrm{EI} \frac{\partial^{4} \mathrm{u}^{*}}{\partial \mathrm{x}^{4}}=\delta(\mathrm{x}-\xi)
$$

one obtains the basic BEM equation, written as:

$$
\begin{gathered}
u(\xi)=\left.\left[u^{*}(\xi, x) Q(x)\right]\right|_{x=L}-\left.\left[u^{*}(\xi, x) Q(x)\right]\right|_{x=0}- \\
{\left.\left[\varphi^{*}(\xi, x) M(x)\right]\right|_{x=L}+\left.\left[\varphi^{*}(\xi, x) M(x)\right]\right|_{x=0}+} \\
{\left.\left[M^{*}(\xi, x) \varphi(x)\right]\right|_{x=L}-\left.\left[M^{*}(\xi, x) \varphi(x)\right]\right|_{x=0}-} \\
{\left.\left[Q^{*}(\xi, x) u(x)\right]\right|_{x=L}+\left.\left[Q^{*}(\xi, x) u(x)\right]\right|_{x=0}+} \\
\int_{0}^{L} u^{*}(\xi, x) q(x) d x
\end{gathered}
$$


Equation (7) already took into account that $M(x)=-E I \frac{d^{2} u}{d x^{2}}$ and $Q(x)=-E I \frac{d^{3} u(x)}{d x^{3}}$, see Equations (4) and (5). The following functions are defined:

$$
\begin{gathered}
\varphi^{*}(\xi, x)=\frac{\partial u^{*}(\xi, x)}{\partial x} \\
M^{*}(\xi, x)=-\operatorname{EI} \frac{\partial^{2} u^{*}(\xi, x)}{\partial x^{2}} \\
Q^{*}(\xi, x)=-E I \frac{\partial^{3} u^{*}(\xi, x)}{\partial x^{3}}
\end{gathered}
$$

The fundamental solution is given by:

$$
u^{*}(\xi, x)=\frac{|x-\xi|^{3}}{12 E I}
$$

and, as usual in the BEM nomenclature, $\mathrm{x}$ is the field point and $\xi$ is the source point.

As the boundary is constituted only by the extreme nodes of the beam, the two equations represented by Equation (7), written for $\xi=0$ and for $\xi=\mathrm{L}$, are not sufficient for the complete solution of the problem. Consequently, two additional equations are required. These equations can be those corresponding to the rotation of the cross-section at the two boundary nodes and are obtained by taking the derivative of Equation (7) with respect to $\xi$. In this way, one has:

$$
\begin{gathered}
\varphi(\xi)=\left.\left[u_{\xi}^{*}(\xi, x) Q(x)\right]\right|_{x=L}-\left.\left[u_{\xi}^{*}(\xi, x) Q(x)\right]\right|_{x=0}- \\
{\left.\left[\varphi_{\xi}^{*}(\xi, x) M(x)\right]\right|_{x=L}+\left.\left[\varphi_{\xi}^{*}(\xi, x) M(x)\right]\right|_{x=0}+} \\
{\left.\left[M_{\xi}^{*}(\xi, x) \varphi(x)\right]\right|_{x=L}-\left.\left[M_{\xi}^{*}(\xi, x) \varphi(x)\right]\right|_{x=0}-} \\
{\left.\left[Q_{\xi}^{*}(\xi, x) u(x)\right]\right|_{x=L}+\left.\left[Q_{\xi}^{*}(\xi, x) u(x)\right]\right|_{x=0}+} \\
\int_{0}^{L} u_{\xi}^{*}(\xi, x) q(x) d x
\end{gathered}
$$

The index $\xi$ in Equation (12) refers to the derivative with respect to the source point coordinate.

After writing Equations (7) and (12) for $\xi=0$ and $\xi=\mathrm{L}$, the problem can be solved. Note that the BEM formulation presents a domain integral, related to the loading, which turns the domain discretization necessary. Linear cells are employed with this purpose and the resulting integrals are evaluated analytically. 
In order to obtain a good picture of the transverse displacements along the beam, the displacements at internal points are computed together with the boundary variables. The resulting system of equation is thus written as follows:

$$
\left[\begin{array}{crc}
\mathbf{H}^{\mathrm{bb}} & -\mathbf{P}^{\mathrm{bb}} & \mathbf{0} \\
\mathbf{0} & \overline{\mathbf{H}}^{\mathrm{bb}} & \mathbf{0} \\
-\mathbf{H}^{\mathrm{db}} & -\mathbf{P}^{\mathrm{db}} & \mathbf{I}
\end{array}\right]\left\{\begin{array}{c}
\mathbf{u}^{\mathrm{b}} \\
\boldsymbol{\varphi}^{\mathrm{b}} \\
\mathbf{u}^{\mathrm{d}}
\end{array}\right\}=\left[\begin{array}{cc}
\mathbf{G}^{\mathrm{bb}} & \mathbf{L}^{\mathrm{bb}} \\
\overline{\mathbf{G}}^{\mathrm{bb}} & \overline{\mathbf{L}}^{\mathrm{bb}} \\
\mathbf{G}^{\mathrm{db}} & \mathbf{L}^{\mathrm{db}}
\end{array}\right]\left\{\begin{array}{c}
\mathbf{Q}^{\mathrm{b}} \\
\mathbf{M}^{\mathrm{b}}
\end{array}\right\}+\left\{\begin{array}{l}
\mathbf{f}^{\mathrm{b}} \\
\overline{\mathbf{f}^{\mathrm{b}}} \\
\mathbf{f}^{\mathrm{d}}
\end{array}\right\}
$$

In Equation (13), the superscript $b$ means boundary, $d$ means domain (internal points) and the double superscript is interpreted as follows: the first is associated with the position of the source point and the second, with the position of the field point. The vector $\mathbf{f}$ is related to the external loading and $\mathbf{I}$ is the identity matrix.

After the imposition of the boundary conditions, the system of equations is solved by employing standard procedures. Together with the boundary variables, the solution also contains the displacements at the internal points.

\section{THE TIMOSHENKO THEORY OF BEAMS}

In the Timoshenko theory of beams, e.g. Graff [6], Rao [7], Timoshenko [8], the effect of the shear deformation is taken into account, generating an improved theory. The plane cross-sections remain plane but not necessarily perpendicular to the neutral axis after bending.

According to this theory, the rotation of the cross-section is made up of two contributions: one, denoted by $\psi$, measures the rotation of the cross-section due to bending whereas the additional contribution, $\gamma_{0}$, is due to the shearing effects. One can write:

$$
\frac{d u}{d x}=\psi+\gamma_{0}
$$

For the system of coordinates described in Figure 1, the governing equations of the problem are written as:

$$
\begin{gathered}
\kappa G A\left(\frac{d^{2} u}{d x^{2}}-\frac{d \psi}{d x}\right)=-q(x) \\
\kappa G A\left(\frac{d u}{d x}-\psi\right)+E I \frac{d^{2} \psi}{d x^{2}}=0
\end{gathered}
$$

In Equations (15) and (16) $\kappa$ is an adjusting coefficient, or corrective factor, designated as shear coefficient, that depends on the shape of the cross-section, see Borges [2], or, according to the approach, on the Poisson coefficient, see Cowper [4]. The coefficient $\kappa$ corrects the error introduced when the shear stresses are assumed to be functions only of the variable $\mathrm{x}$, that is, when not taking into account their variation in the cross-section. Additionally, $\mathrm{G}$ is 
the shear modulus. The other constants that appear in Equations (15) and (16) are the same that have already appeared in Equation (1).

The boundary conditions are:

$$
\begin{aligned}
& \mathrm{u}(\mathrm{x})=\overline{\mathrm{u}}(\mathrm{x}) \text { : transverse displacement } \\
& \psi(\mathrm{x})=\bar{\psi}(\mathrm{x}) \text { : rotation due to bending } \\
& -\mathrm{EI} \frac{\mathrm{d} \psi}{\mathrm{dx}}=\overline{\mathrm{M}}(\mathrm{x}) \text { : bending moment } \\
& \kappa \mathrm{GA}\left(\frac{\mathrm{du}}{\mathrm{dx}}-\psi\right)=\overline{\mathrm{Q}}(\mathrm{x}) \text { : shear force }
\end{aligned}
$$

\subsection{BEM Formulation to the Timoshenko Beam}

In order to develop a BEM formulation for the Timoshenko beam theory, Equations (15) and (16) are considered separately and, for each one, a corresponding integral equation is written. In this formulation the presence of domain integrals, other than that related to the loading, turns the domain discretization imperative and, consequently, the final system of equations contains the variables at the internal points.

Applying a residual statement to Equation (15), in which the weighting function is the fundamental solution that satisfies Equation (21) below:

$$
\frac{\partial^{2} u^{*}}{\partial x^{2}}=\delta(x-\xi)
$$

one obtains:

$$
\begin{gathered}
u(\xi)=\left.\left[\frac{\partial u^{*}(\xi, x)}{\partial x} u(x)\right]\right|_{x=L}-\left.\left[\frac{\partial u^{*}(\xi, x)}{\partial x} u(x)\right]\right|_{x=0}- \\
{\left[\left.u^{*}(\xi, x) \frac{d u(x)}{d x}\right|_{x=L}+\left.\left[u^{*}(\xi, x) \frac{d u(x)}{d x}\right]\right|_{x=0}+\right.} \\
\int_{0}^{L} u^{*}(\xi, x) \frac{d \psi(x)}{d x} d x- \\
\frac{1}{\kappa G A} \int_{0}^{L} u^{*}(\xi, x) q(x) d x
\end{gathered}
$$

Integrating by parts the first domain integral, one has:

$$
\int_{0}^{\mathrm{L}} \mathrm{u}^{*}(\xi, \mathrm{x}) \frac{\mathrm{d} \psi(\mathrm{x})}{\mathrm{dx}} \mathrm{dx}=\left[\mathrm{u}^{*}(\xi, \mathrm{x}) \psi(\mathrm{x})\right]_{\left.\right|_{\mathrm{x}=\mathrm{L}}}-\left[\mathrm{u}^{*}(\xi, \mathrm{x}) \psi(\mathrm{x})\right]_{\left.\right|_{\mathrm{x}=0}}-
$$




$$
\int_{0}^{\mathrm{L}} \frac{\partial \mathrm{u}^{*}(\xi, \mathrm{x})}{\partial \mathrm{x}} \psi(\mathrm{x}) \mathrm{dx}
$$

Substituting Equation (23) into Equation (22), the latter is rewritten as:

$$
\begin{gathered}
u(\xi)=\left.\left[\frac{d u^{*}(\xi, x)}{d x} u(x)\right]\right|_{x=L}-\left[\left.\frac{d u^{*}(\xi, x)}{d x} u(x)\right|_{x=0}-\right. \\
{\left[u^{*}(\xi, x)\left(\frac{d u(x)}{d x}-\psi(x)\right)\right]_{x=L}+\left.\left[u^{*}(\xi, x)\left(\frac{d u(x)}{d x}-\psi(x)\right)\right]\right|_{x=0}-} \\
\int_{0}^{L} \frac{\partial u^{*}(\xi, x)}{\partial x} \psi(x) d x- \\
\frac{1}{\kappa G A} \int_{0}^{L} u^{*}(\xi, x) q(x) d x
\end{gathered}
$$

Bearing in mind the expression for the shear force, Equation (20), one finally has:

$$
\begin{gathered}
u(\xi)=\left.\left[\frac{d u^{*}(\xi, x)}{d x} u(x)\right]\right|_{x=L}-\left.\left[\frac{d u^{*}(\xi, x)}{d x} u(x)\right]\right|_{x=0}- \\
{\left[\left.u^{*}(\xi, x) \frac{Q(x)}{\kappa G A}\right|_{x=L}+\left.\left[u^{*}(\xi, x) \frac{Q(x)}{\kappa G A}\right]\right|_{x=0}-\right.} \\
\int_{0}^{L} \frac{\partial u^{*}(\xi, x)}{\partial x} \psi(x) d x- \\
\frac{1}{\kappa G A} \int_{0}^{L} u^{*}(\xi, x) q(x) d x
\end{gathered}
$$

The fundamental solution is given by:

$$
\mathrm{u}^{*}(\xi, \mathrm{x})=\frac{|\mathrm{x}-\xi|^{2}}{2}
$$

Before applying a residual statement to Equation (16), it is initially rewritten as follows:

$$
\frac{d^{2} \psi}{d x^{2}}-\beta \psi+\beta \frac{d u}{d x}=0
$$

where:

$$
\beta=\frac{\kappa \mathrm{GA}}{\mathrm{EI}}
$$

The fundamental solution, by this time, is the solution of the equation: 


$$
\frac{\partial^{2} \psi^{*}(\xi, x)}{\partial x^{2}}-\beta \psi^{*}(\xi, x)=0
$$

and is given by:

$$
\psi^{*}(\xi, x)=\frac{\sinh \sqrt{\beta}|x-\xi|}{2 \sqrt{\beta}}
$$

After applying a residual statement to Equation (27), and taking into account Equation (29), one has:

$$
\begin{gathered}
\psi(\xi)=\left[\frac{\partial \psi^{*}(\xi, \mathrm{x})}{\partial \mathrm{x}} \psi(\mathrm{x})\right]_{\mathrm{x}=\mathrm{L}}-\left[\frac{\partial \psi^{*}(\xi, \mathrm{x})}{\partial \mathrm{x}} \psi(\mathrm{x})\right] \mathrm{I}_{\mathrm{x}=0}- \\
{\left.\left[\psi^{*}(\xi, \mathrm{x}) \frac{\mathrm{d} \psi(\mathrm{x})}{\mathrm{dx}}\right]\right|_{\mathrm{x}=\mathrm{L}}+\left.\left[\psi^{*}(\xi, \mathrm{x}) \frac{\mathrm{d} \psi(\mathrm{x})}{\mathrm{dx}}\right]\right|_{\mathrm{x}=0}-} \\
\beta \int_{0}^{\mathrm{L}} \psi^{*}(\xi, \mathrm{x}) \frac{\mathrm{du}(\mathrm{x})}{\mathrm{dx}} \mathrm{dx}
\end{gathered}
$$

The domain integral is integrated by parts, giving:

$$
\begin{gathered}
\int_{0}^{\mathrm{L}} \psi^{*}(\xi, \mathrm{x}) \frac{\mathrm{du}(\mathrm{x})}{\mathrm{dx}} \mathrm{dx}=\left.\left[\psi^{*}(\xi, \mathrm{x}) \mathrm{u}(\mathrm{x})\right]\right|_{\mathrm{x}=\mathrm{L}}-\left.\left[\psi^{*}(\xi, \mathrm{x}) \mathrm{u}(\mathrm{x})\right]\right|_{\mathrm{x}=0}- \\
\int_{0}^{\mathrm{L}} \frac{\partial \psi^{*}(\xi, \mathrm{x})}{\partial \mathrm{x}} \mathrm{u}(\mathrm{x}) \mathrm{dx}
\end{gathered}
$$

Substituting Equation (32) into Equation (31) comes:

$$
\begin{gathered}
\psi(\xi)=\left[\frac{\partial \psi^{*}(\xi, \mathrm{x})}{\partial \mathrm{x}} \psi(\mathrm{x})\right]_{\mathrm{x}=\mathrm{L}}-\left.\left[\frac{\partial \psi^{*}(\xi, \mathrm{x})}{\partial \mathrm{x}} \psi(\mathrm{x})\right]\right|_{\mathrm{x}=0}- \\
{\left[\psi^{*}(\xi, \mathrm{x}) \frac{\mathrm{d} \psi(\mathrm{x})}{\mathrm{dx}}\right]_{\mathrm{x}=\mathrm{L}}+\left.\left[\psi^{*}(\xi, \mathrm{x}) \frac{\mathrm{d} \psi(\mathrm{x})}{\mathrm{dx}}\right]\right|_{\mathrm{x}=0}-} \\
\left.\beta\left[\psi^{*}(\xi, \mathrm{x}) \mathrm{u}(\mathrm{x})\right]\right|_{\mathrm{x}=\mathrm{L}}+\left.\beta\left[\psi^{*}(\xi, \mathrm{x}) \mathrm{u}(\mathrm{x})\right]\right|_{\mathrm{x}=0}+ \\
\beta \int_{0}^{\mathrm{L}} \frac{\partial \psi^{*}(\xi, \mathrm{x})}{\partial \mathrm{x}} \mathrm{u}(\mathrm{x}) \mathrm{dx}
\end{gathered}
$$

The final integral equation, written after taking into account the expression for the bending moment, given by Equation (19), is written below:

$$
\psi(\xi)=\left[\frac{\partial \psi^{*}(\xi, \mathrm{x})}{\partial \mathrm{x}} \psi(\mathrm{x})\right]_{\mathrm{x}=\mathrm{L}}-\left[\frac{\partial \psi^{*}(\xi, \mathrm{x})}{\partial \mathrm{x}} \psi(\mathrm{x})\right]_{\left.\right|_{x=0}}+
$$




$$
\begin{gathered}
{\left.\left[\psi^{*}(\xi, \mathrm{x}) \frac{\mathrm{M}(\mathrm{x})}{\mathrm{EI}}\right]\right|_{\mathrm{x}=\mathrm{L}}-\left.\left[\psi^{*}(\xi, \mathrm{x}) \frac{\mathrm{M}(\mathrm{x})}{\mathrm{EI}}\right]\right|_{\mathrm{x}=0}-} \\
\left.\beta\left[\psi^{*}(\xi, \mathrm{x}) \mathrm{u}(\mathrm{x})\right]\right|_{\mathrm{x}=\mathrm{L}}+\left.\beta\left[\psi^{*}(\xi, \mathrm{x}) \mathrm{u}(\mathrm{x})\right]\right|_{\mathrm{x}=0}+ \\
\beta \int_{0}^{\mathrm{L}} \frac{\partial \psi^{*}(\xi, \mathrm{x})}{\partial \mathrm{x}} \mathrm{u}(\mathrm{x}) \mathrm{dx}
\end{gathered}
$$

In this formulation, the presence of two domain integrals beside the loading domain integral, see Equations (25) and (34) turns the domain discretization imperative. Consequently, in the final system of equation the values of the displacement and of the rotation $\psi$ at the internal points appear as unknowns together with the boundary unknowns.

The system of equations is written below:

$$
\left[\begin{array}{cccc}
\mathbf{H}^{\mathrm{bb}} & \mathbf{P}^{\mathrm{bb}} & \mathbf{0} & \mathbf{P}^{\mathrm{bd}} \\
-\overline{\mathbf{P}}^{\mathrm{bb}} & \overline{\mathbf{H}}^{\mathrm{bb}} & -\overline{\mathbf{P}}^{\mathrm{bd}} & \mathbf{0} \\
-\mathbf{H}^{\mathrm{db}} & \mathbf{P}^{\mathrm{db}} & \mathbf{I} & \mathbf{P}^{\mathrm{dd}} \\
-\overline{\mathbf{P}}^{\mathrm{db}} & -\overline{\mathbf{H}}^{\mathrm{db}} & -\overline{\mathbf{P}}^{\mathrm{dd}} & \mathbf{I}
\end{array}\right]\left\{\begin{array}{l}
\mathbf{u}^{\mathrm{b}} \\
\boldsymbol{\Psi}^{\mathrm{b}} \\
\mathbf{u}^{\mathrm{d}} \\
\boldsymbol{\Psi}^{\mathrm{d}}
\end{array}\right\}=\left[\begin{array}{cc}
\mathbf{L}^{\mathrm{bb}} & \mathbf{0} \\
\mathbf{0} & \overline{\mathbf{G}}^{\mathrm{bb}} \\
\mathbf{L}^{\mathrm{db}} & \mathbf{0} \\
\mathbf{0} & \overline{\mathbf{G}}^{\mathrm{db}}
\end{array}\right]\left\{\begin{array}{l}
\mathbf{Q}^{\mathrm{b}} \\
\mathbf{M}^{\mathrm{b}}
\end{array}\right\}+\left\{\begin{array}{l}
\mathbf{f}^{\mathrm{b}} \\
\mathbf{0} \\
\mathbf{f}^{\mathrm{d}} \\
\mathbf{0}
\end{array}\right\}
$$

The superscripts $b$ and $d$ in Equation (35) have the same interpretation of that in Equation (13). The terms $\mathbf{u}^{\mathrm{d}}$ and $\psi^{\mathrm{d}}$ appear due to the domain integrals in Equations (25) and (34). The vector $\mathbf{f}$ is related to the external loading.

\section{NUMERICAL EXAMPLES}

The numerical examples deal with a concrete beam with length $\mathrm{L}=4.0 \mathrm{~m}$ for the cases of pinned-pinned, fixed-fixed and fixed-pinned beams. For the case of fixed-free beam, ones has $\mathrm{L}=2.0 \mathrm{~m}$. The material is the concrete with $\mathrm{E}=50 \mathrm{GPa}$; the Poisson ratio is $v=0.2$. The cross-section is a rectangular one, with height $\mathrm{h}=0.60 \mathrm{~m}$ and width $\mathrm{b}=0.20 \mathrm{~m}$. Consequently, $\mathrm{I}=0.0036 \mathrm{~m}^{4}$ and $\mathrm{A}=0.12 \mathrm{~m}^{2}$. The loading, uniformly distributed along the length of the beam, is given by $q(x)=q=100 \mathrm{kN} / \mathrm{m}$.

\subsection{Euler-Bernoulli beams}

Initially, the results concerned with the Euler-Bernoulli theory are presented. As mentioned earlier, the discretization is due to the loading and the number of internal points can be chosen only to provide a good picture of the behaviour of the transversal displacements along the length of the beam. For this reason, in all analyses 15 internal points equally spaced were selected, which means that the domain was discretized by employing 16 cells of the same length.

The analytical solutions are presented below, see Fleischfresser [5]: 
i) pinned-pinned beam:

$$
u(x)=\frac{q}{24 E I}\left(x^{4}-2 L x^{3}+L^{3} x\right)
$$

ii) fixed-fixed beam:

$$
u(x)=\frac{q}{24 E I}\left(x^{4}-2 L x^{3}+L^{2} x^{2}\right)
$$

iii) fixed-pinned beam:

$$
u(x)=\frac{q}{48 E I}\left(2 x^{4}-5 L x^{3}+3 L^{2} x^{2}\right)
$$

iv) fixed-free beam:

$$
u(x)=\frac{q}{24 E I}\left(x^{4}-4 L x^{3}+6 L^{2} x^{2}\right)
$$

The next four figures present the results related, respectively, to the pinned-pinned, fixed-fixed, fixed-pinned and fixed-free beams.

The agreement between the analytical and numerical results is noticeable.

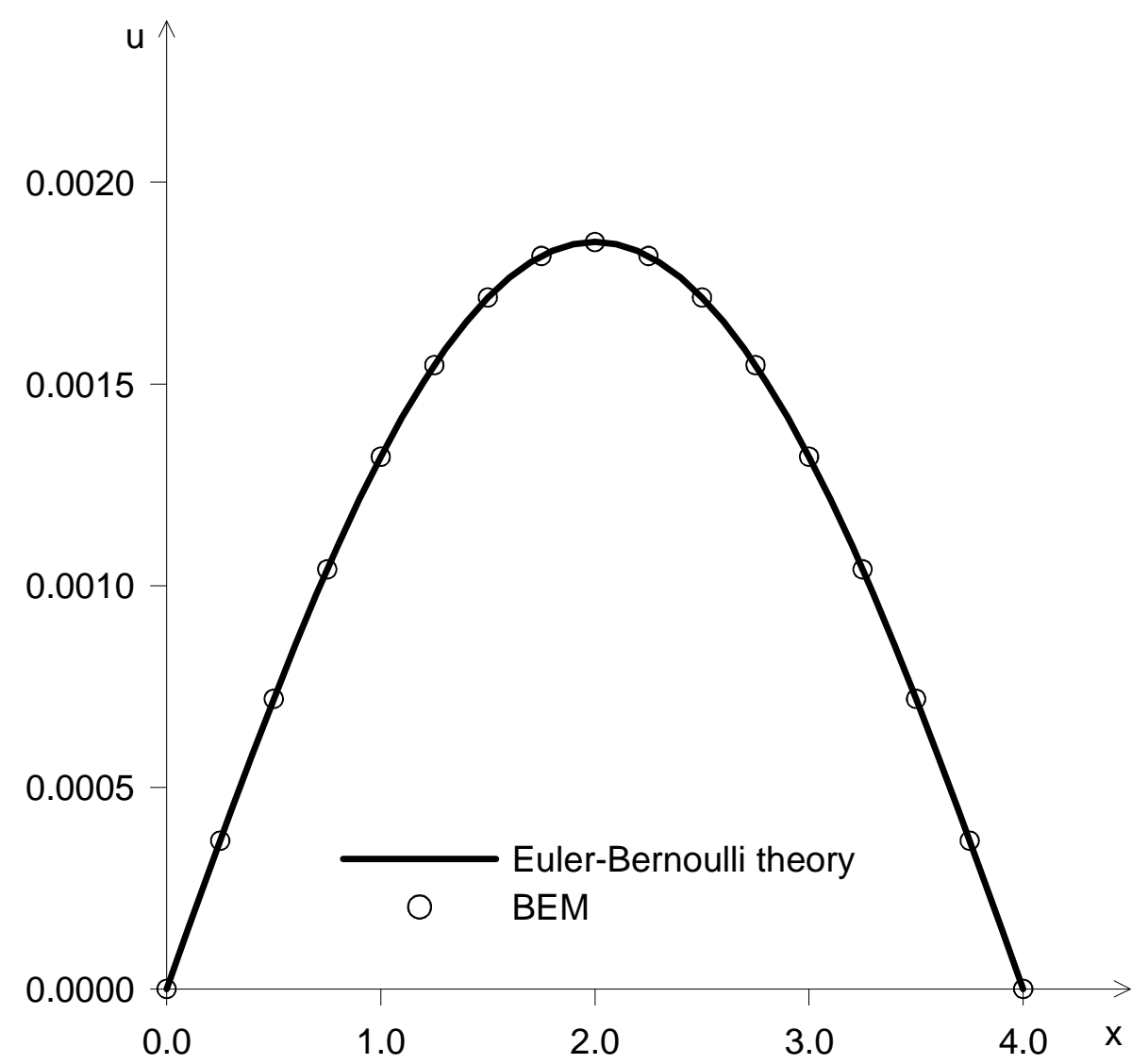

Figure 2. Euler-Bernoulli theory: pinned-pinned beam. 


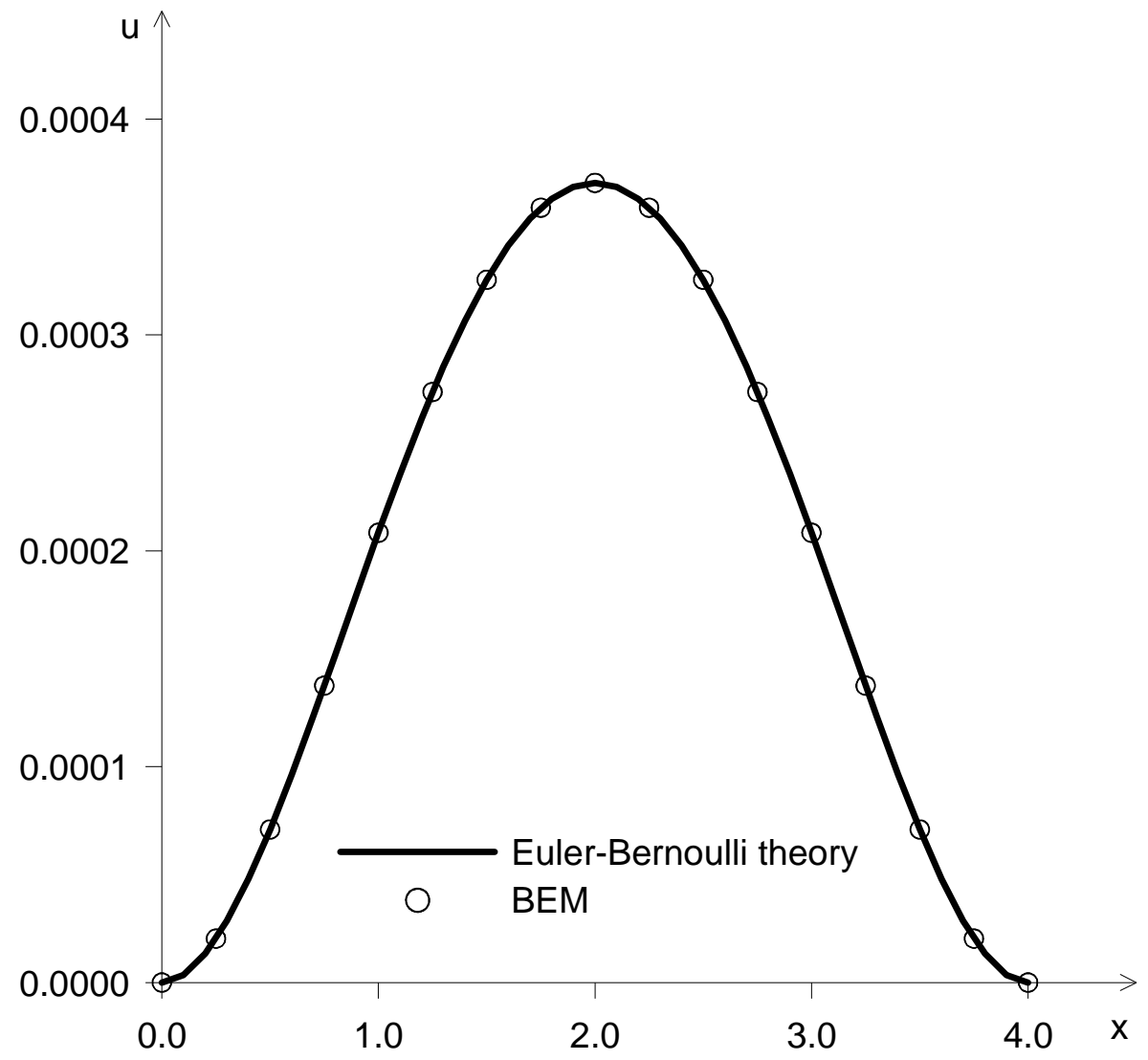

Figure 3. Euler-Bernoulli theory: fixed-fixed beam.

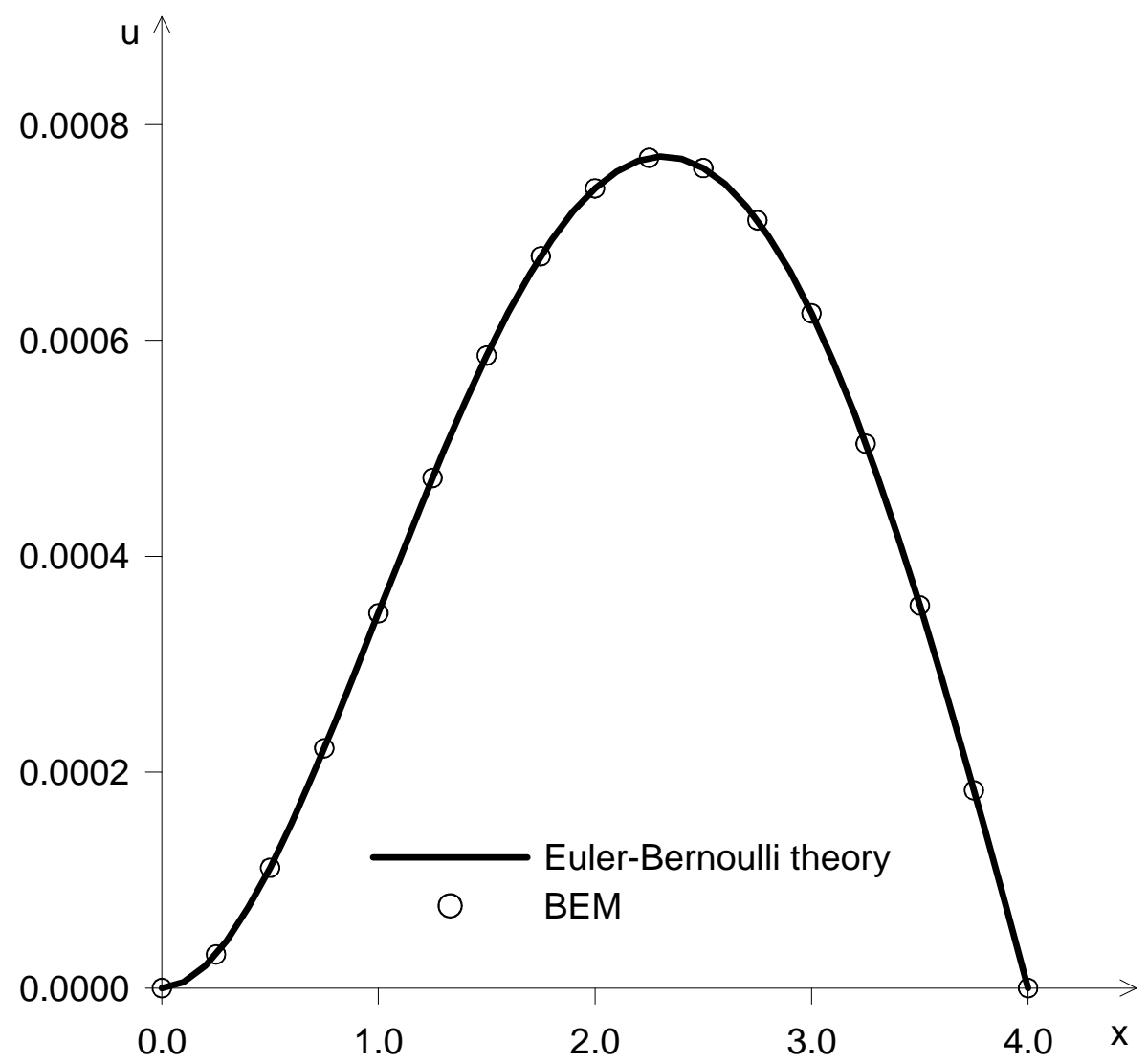

Figure 4. Euler-Bernoulli theory: fixed-pinned beam. 


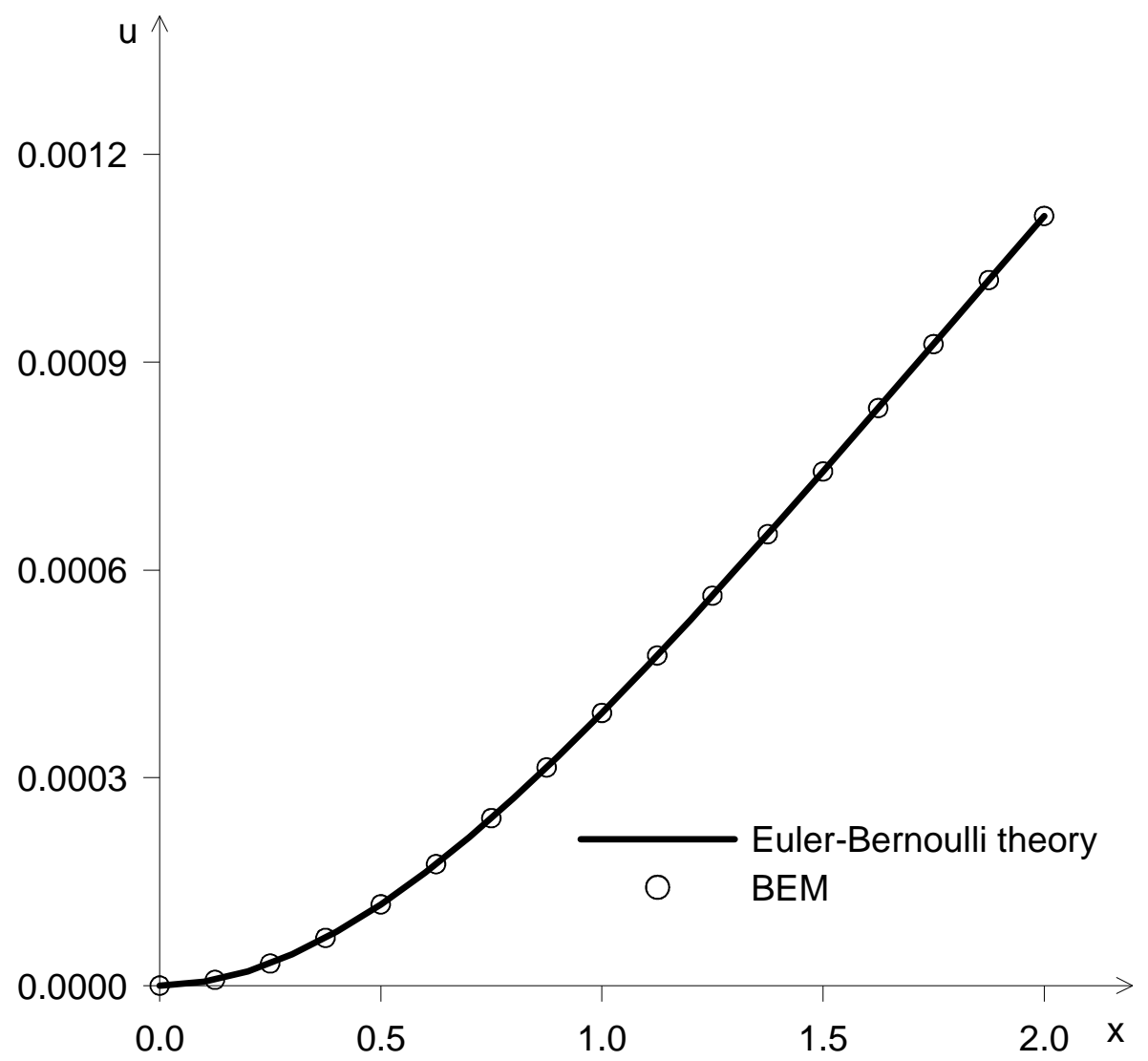

Figure 5. Euler-Bernoulli theory: fixed-free beam.

\subsection{Timoshenko beams}

The analytical solution of the Timoshenko beams is constituted by two parcels: the first one, related to the bending effect, is equal to the analytical solution of the EulerBernoulli beams; the second one is related to the shear effect. This form of the analytical solution appears quite naturally in the solution of the system of equations represented by Equations (15) and (16). The exception occurs for the fixed-pinned beam: here, some algebraic manipulations were carried out to represent its analytical solution as the sum of the EulerBernoulli solution with two other parcels. The reader is referred to Fleischfresser [5] for additional details on this subject. The expressions of the analytical solutions are given below:

i) pinned-pinned beam:

$$
u(x)=\frac{q}{24 E I}\left(x^{4}-2 L x^{3}+L^{3} x\right)+\frac{q}{2 \kappa G A}\left(L x-x^{2}\right)
$$

ii) fixed-fixed beam:

$$
u(x)=\frac{q}{24 E I}\left(x^{4}-2 L x^{3}+L^{2} x^{2}\right)+\frac{q}{2 \kappa G A}\left(L x-x^{2}\right)
$$


iii) fixed-pinned beam:

$$
\begin{gathered}
u(x)=\frac{q}{48 E I}\left(2 x^{4}-5 L x^{3}+3 L^{2} x^{2}\right)+\frac{q D_{f p}}{48 E I}\left(L x^{3}-3 L^{2} x^{2}\right)- \\
\frac{q}{2 \kappa G A}\left(x^{2}+2 C_{f p} L x\right)
\end{gathered}
$$

where

$$
\mathrm{C}_{\mathrm{fp}}=-\frac{5 \kappa \mathrm{GAL}^{2}+12 \mathrm{EI}}{8 \kappa \mathrm{GAL}^{2}+24 \mathrm{EI}}
$$

and

$$
D_{\mathrm{fp}}=\frac{3 \mathrm{EI}}{\kappa G A L^{2}+3 E I}
$$

$i v)$ fixed-free beam:

$$
u(x)=\frac{q}{24 E I}\left(x^{4}-4 L x^{3}+6 L^{2} x^{2}\right)+\frac{q}{2 \kappa G A}\left(2 L x-x^{2}\right)
$$

Due to the domain integrals containing the variable $\psi$ in Equation (25) and the variable $\mathrm{u}$ in Equation (34), a good refinement of the domain is required in order to obtain accurate results. For the pinned-pinned, fixed-fixed and fixed-pinned beams three analyses were carried out by employing 16, 32 and 64 cells with the same length, whereas for the fixed-free beam the analyses were carried out by employing 8,16 and 32 cells, as the length of the beam, in this case, is half the length of the others and it seemed reasonable to keep the ratio between the length of the cells and the length of the beam constant at each level of refinement. The convergence of the BEM results to the analytical solutions can be observed in the next four figures.

The shear coefficient, for the rectangular cross-section, adopted in all examples, is given by, see Borges [2]:

$$
\kappa=\frac{5}{6}
$$

It is important to mention that the main concern of this work is to prove that both formulations can produce reliable results. For this reason, the same beam, that is, a beam with same rectangular cross-section, was considered in all analysis. As can be observed from Figures 2 to 9, the difference between the results, for similar beams, is not so significant as could be expected. This happens because the ratio $\mathrm{h} / \mathrm{L}=0.15$ (or $\mathrm{h} / \mathrm{L}=0.30$ for the fixed-free beam) is small and enables the use of the classical theory of beams. Anyway, regarding the applicability of the formulations, it is the authors' opinion that the goal was achieved. 


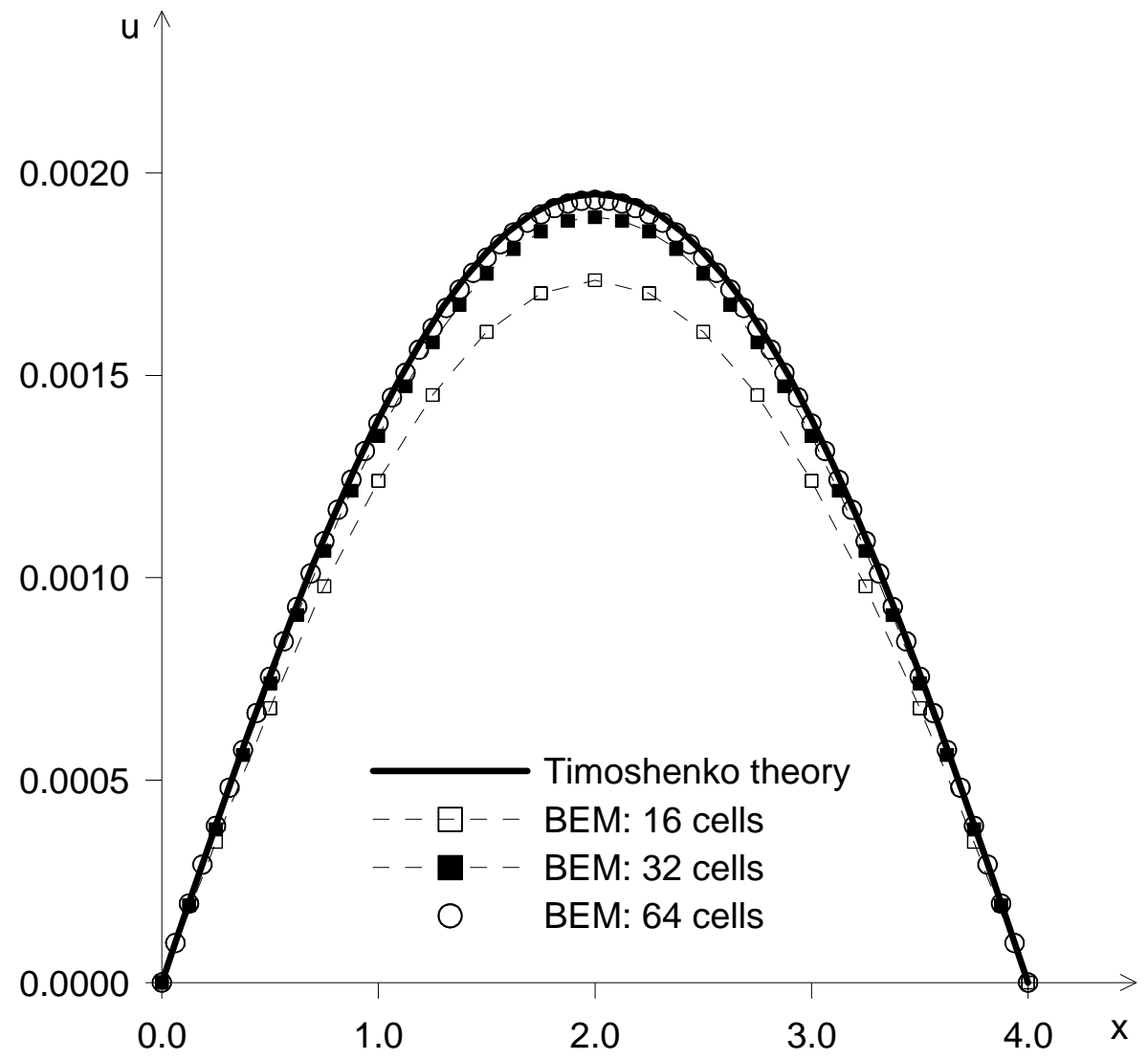

Figure 6. Timoshenko theory: pinned-pinned beam.

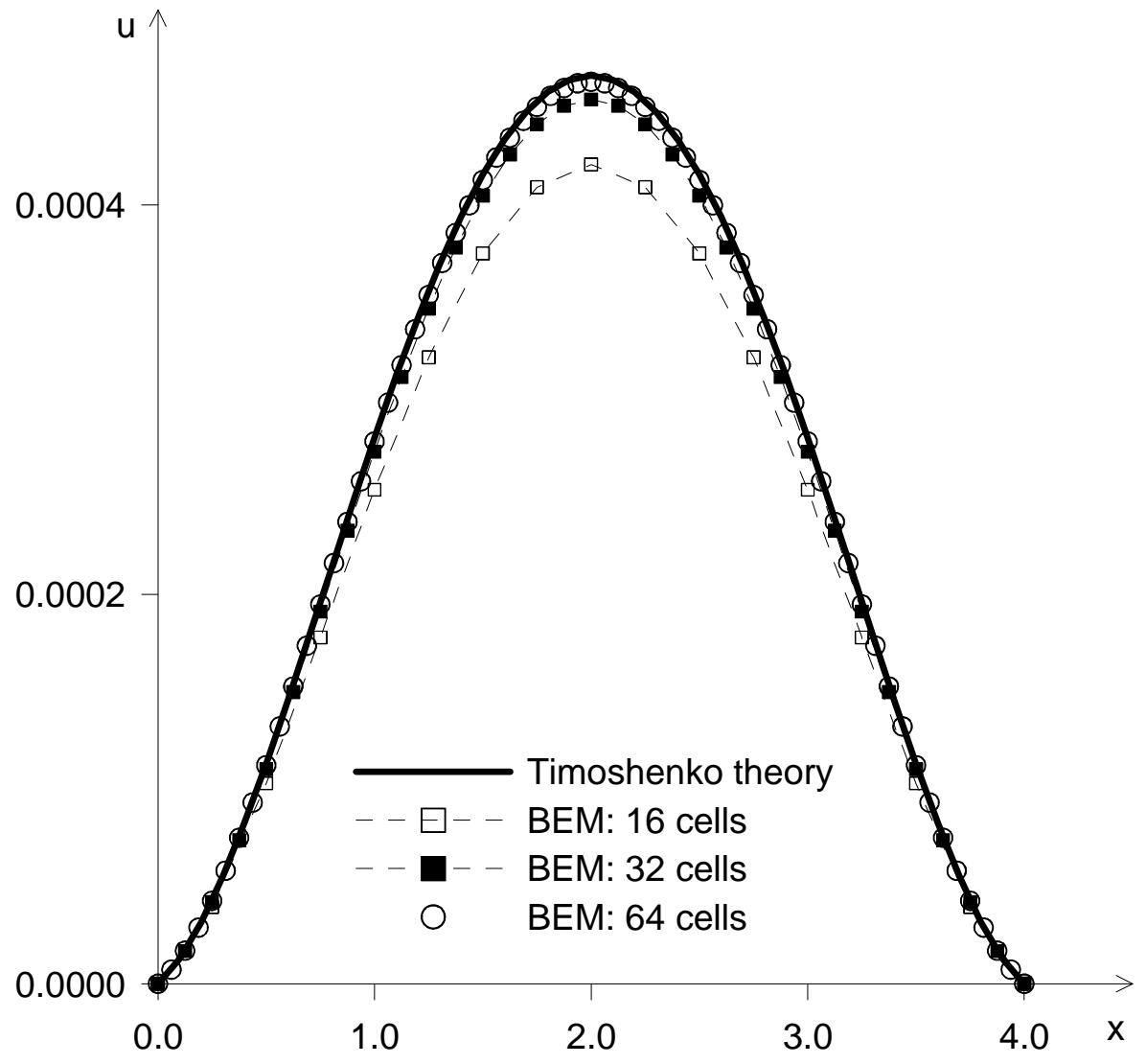

Figure 7. Timoshenko theory: fixed-fixed beam. 


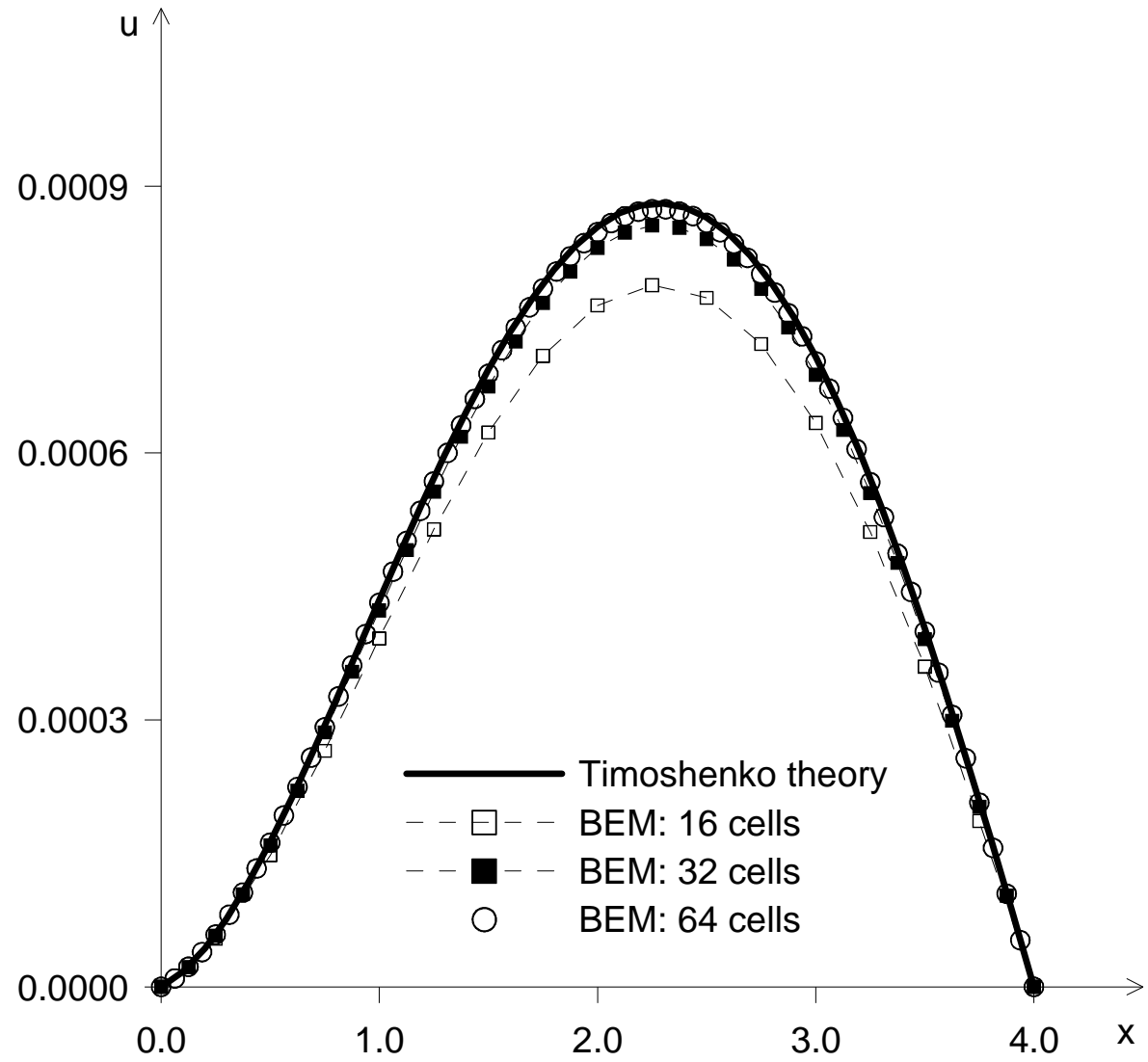

Figure 8. Timoshenko theory: fixed-pinned beam.

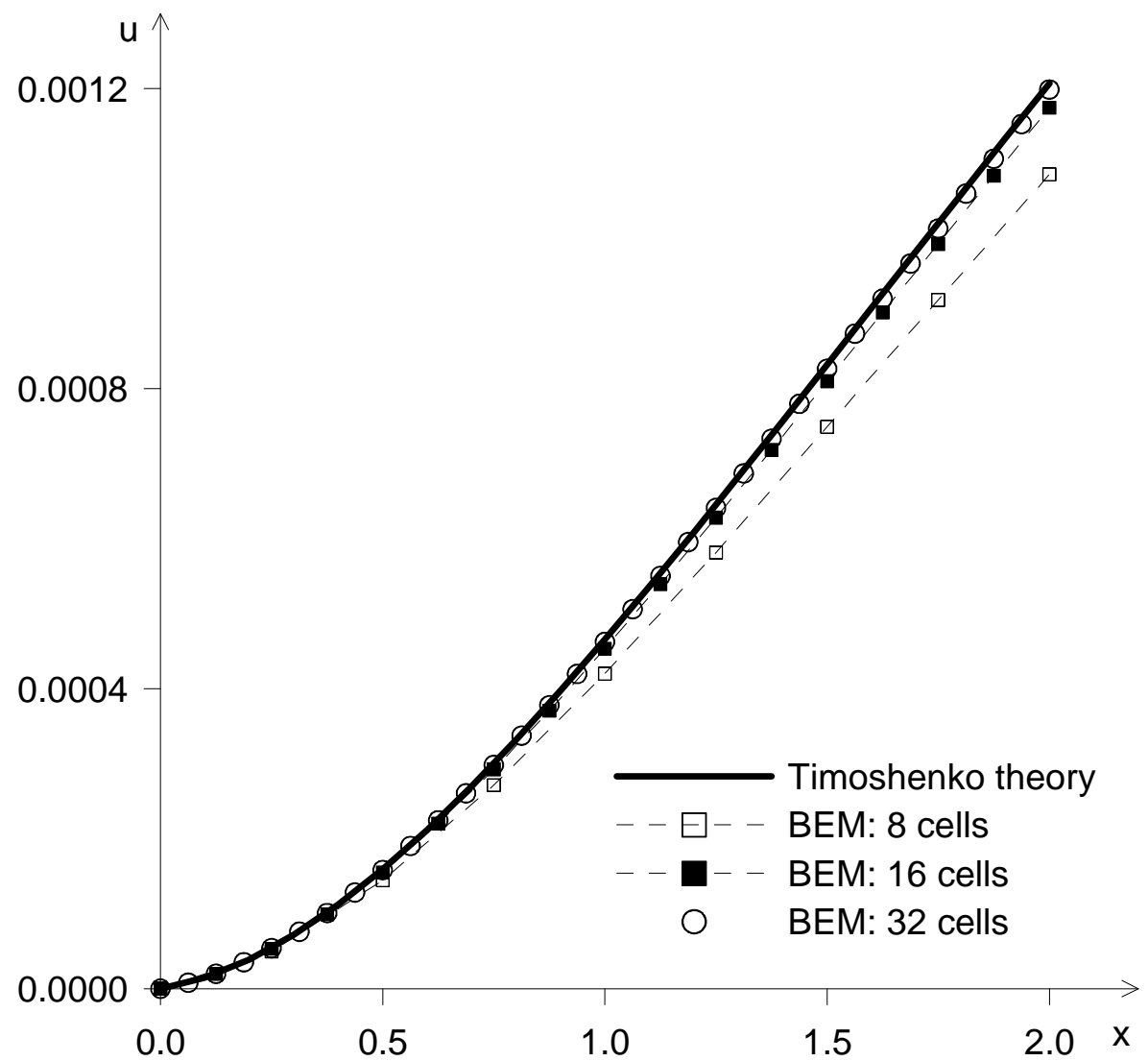

Figure 9. Timoshenko theory: fixed-free beam. 


\section{CONCLUSIONS}

This work is concerned with the development of two BEM formulations for static analysis of beams. The first formulation is related to the Euler-Bernoulli, or classical, theory of beams. For the usual kinds of beams, the BEM results presented a good agreement with the analytical ones. The computation of the displacements at internal points is carried out only with the purpose to provide a good description of the behaviour of the displacements along the length of the beam. Note that if only the results at the boundary nodes were required, the domain could be discretized with only one cell. The second formulation is related to the Timoshenko theory of beams. Here, diversely from the first formulation, the domain discretization is required due to the presence, in the integral equations of the formulation, of domain integrals containing the displacement, $\mathrm{u}$, and the rotation due to bending, $\psi$. Linear cells were employed for this purpose. Although the results converged to the analytical solution in all examples, it seems reasonable to suppose that the use of interpolation functions with degree higher than one could improve even more the convergence and, consequently, the accuracy of the results. Another kind of loading, that is, the concentrated loading, can be taken into account without difficulty. Dynamic analysis of Euler-Bernoulli and Timoshenko beams is a very interesting subject that also deserves attention.

\section{REFERENCES}

[1] Antes H., "Fundamental Solution and Integral Equations for Timoshenko Beams". Computers and Structures 81, 383-396, 2003.

[2] Borges M. S. S., “Análise do Efeito da Deformabilidade por Cisalhamento na Flexão de Vigas - Formulação Geral do Problema e Determinação do Coeficiente de Cisalhamento". Seminário para Qualificação ao Doutorado, COPPE/UFRJ, Rio de Janeiro, RJ, Brasil, 1996.

[3] Brebbia C. A., Telles J. C. F., Wrobel L. C., "Boundary Element Techniques: Theory and Applications in Engineering". Springer-Verlag, Berlin, Heidelberg, New York, Tokyo, 1984.

[4] Cowper G. R., “The Shear Coefficient in Timoshenko's Beam Theory". Journal of Applied Mechanics 33, 335-340, 1966.

[5] Fleischfresser S. A., “Análise do Efeito da Deformabilidade por Cisalhamento na Flexão de Vigas: uma Formulação do Método dos Elementos de Contorno para Vigas de Timoshenko". Seminário para Qualificação ao Doutorado, PPGMNE/UFPR, Curitiba, PR, Brasil, 2012.

[6] Graff K. F., "Wave Motion in Elastic Solids”. Dover Publications, New York, 1991.

[7] Rao S. S., "Mechanical Vibrations". Addison-Wesley Publishing Company, $3^{\text {rd }}$ Edition, 
1995.

[8] Timoshenko S. P., "On the Correction for Shear of the Differential Equation for Transverse Vibrations of Prismatic Bars". Philosophical Magazine 41, 744-746, 1921. 